\title{
Training needs of general library workers Part 2: challenges facing the public library sector in South Africa
}

\author{
Hester WJ Meyer' \\ Department of Information Science, University of South Africa \\ meyerhwj@gmail.com
}

\begin{abstract}
Received: 20 September 2010
Accepted: 20 November 2010

This article, the second of two, deals with the training needs of general library workers in the South African public library sector. The first appear in this Journal 76(I). This one considers the types of tasks that general library workers perform, the skills required, and the standards and expectations within the working environment. Data were collected by means of a self-administered questionnaire directed at supervisory staff of provincial and municipal libraries. Interviews conducted with supervisors and a careful study of job descriptions was compared to the results of the survey to ensure validity. The findings revealed that supervisory staff members who used to offer in-service training to general library workers now increasingly have trouble with new entrants who are not "work-ready". The results show a preference for a learning programme - either formal or non-formal - with a strong vocational component. A need for closer relations between practitioners and educators to negotiate logistics in terms of the completion of the practical component of the programme is envisioned.
\end{abstract}

Keywords: General library workers; public libraries; training needs; education for general workers

\section{Introduction}

Compared to the training of the professional workforce in the field of library and information science (LIS), it is evident that institutions of higher education in South Africa have paid scant attention to formal learning programmes for general library workers in the past. This is a cause of concern for LIS educators as higher education institutions should cater for the needs of market systems. It is argued that if these institutions fail to do so, they will most probably fail to honour their educational mandate (Engelbrecht 2003).

Within the context of a library, general library workers act in a capacity of support to management. Although the workers do not need prior training to be appointed, they need to have a basic understanding of the relevant sources, functions, processes and procedures of a library to enable it to render an effective service to its clients. If workers do not perform their tasks properly owing to ignorance or inexperience, the workflow of different sections can be delayed which will eventually compromise productivity. The tasks performed are of a routine nature and require demonstration of practical skills that can be easily learned while executing these tasks. Normally, general library workers obtain competencies through in-service training offered by supervisory staff. However, current staff shortages and a variety of changes within the environment of public and related libraries make it increasingly difficult for supervisory staff to ensure that the in-service training of general library workers is offered on a regular basis. Therefore, supervisory staff members have often expressed the desire rather to have "work-ready" staff appointed than having to spend excessive time and effort on inexperienced entrants.

In the first article of this two-part focus on training needs of general library workers (Meyer 2010), it became evident that in South Africa, the former technikons - that have ceased to exist in their original form after 2004 - primarily offered opportunities for tertiary training of general library workers. The training included national certificate programmes in library and information studies (NCLIS). This implies that the opportunities for general library workers to obtain a formal qualification were curtailed.

The Department of Information Science at Unisa in particular is concerned about the training of general library workers because changes were effected to its learning programmes after it had merged with the Department of Library and Information Studies of the former TSA (Meyer 2010). Owing to the merger, Unisa had to phase out the national certificate programme in library and information studies (NCLIS) because it served as an exit level of a degree programme. The practice of module sharing was no longer acceptable to the Higher Education Qualifications Framework (HEQF). In addition, credits assigned to some of the modules of the certificate programme of the former Technikon SA were not always compliant with those of the first-level modules of a bachelor's degree at a university.

Interest in the reintroduction of training of general library workers was also sparked off by the amendments to the Higher Education Act (Act No I0I of 1997) (Department of Education 2007). These amendments have enabled

I. Hester Meyer $(\mathrm{PhD})$ is an Associate Professor in the Department of Information Science, University of South Africa, Pretoria. 
universities to offer certificate learning programmes with a strong vocational component to candidates without the necessary admission exemption of a conventional university qualification. This implied that training for general library workers could be offered by a university should the relevant academic department comply with HEQF criteria and the internal requirements of its institution.

To determine whether a real need existed for training of general library workers, a survey was conducted in 2008 on behalf of the Department of Information Science at Unisa (Meyer 2009). The purpose of this article is to report on the outcomes of the survey, and to reflect on challenges that educators in LIS will have to consider when developing a suitable learning programme for general library workers.

\section{Background and problem statement}

Library work depends heavily on real-life applications of knowledge and skills to create, seek, store and communicate information. It is therefore understandable why so much prominence is given to skills development in literature on LIS education worldwide. Despite the fact that education of LIS professionals has received substantial coverage in literature (Wilson, Kennan, Willard \& Boell 2010; Gerolimos 2009; Bates, Bates \& Bates 2007; Luo 2007; Ashcroft 2004; Fisher 2004; Blankson-Hermans \& Hibberd 2004; Middleton 2003; Biddiscombe 200I), very little is known about educational programmes for, or training needs of general library workers in public and related libraries. In order to put into perspective the existing state of training needs of the latter in the South African context, the following aspects will be considered:

\subsection{Definition of a general library worker}

Although there might be a difference in terms of qualifications, the terms "library assistant" and "library support staff" are often used interchangeably with general library workers. General library workers seemingly form that part of a library's personnel that are assigned to routine tasks that do not require knowledge of and skills in professional library functions and activities. To be appointed as a general library worker, candidates only have to demonstrate proficiency in the critical cross-field skills of reading, writing and numeracy expected of school leavers at Grade 12 level, or an equivalent (Department of Education 2007). In terms of qualified library staff in the LIS industry, a recent investigation conducted for the Department of Arts and Culture (2010:72) reports that the majority of library assistants have NQF (Grade 12) qualifications; however, as many as $13.1 \%$ did not have a Grade 12 qualification.

While the admission criteria might sound fair as far as the type of task and costing of library staff are concerned, the very nature of work in a library requires an understanding of information literacy skills that are not necessarily covered by the basic literacy skills requirements of Grade 12. Although general library workers supposedly perform only routine tasks, they have to work alongside professional staff. It is only to be expected that professional staff will take it for granted that all workers have the same background knowledge of the profession and are familiar with library procedures. Bates et al. (2007:121) refer to a workplace culture of traditions, rules, sanction systems and expectations that need to be accepted and respected, thus largely confirming this perception. The implications of this perception for general library workers are that they are exposed to a community of practices of which they have no background knowledge and that they need to come to grips with the criteria of the profession while performing routine tasks applicable within a library setting.

In the past, supervisory staff of individual libraries initially undertook the training of general library workers. In fact, professional training of library staff in general was initially offered as a diploma of the South African Library Association (SALA). The distance learning diploma qualification of SALA was later transferred to Unisa (South African Library Association 1961:24-25). Librarianship as an academic qualification was introduced in 1949 in South Africa as a bachelor's degree at the University of Pretoria (Biblioteekkunde 1949 1960:126). However, a formal qualification for general workers came much later - integrated in the National Certificate for Library and Information Studies (NCLIS), which was introduced by technikon programmes in South Africa. However, for reasons already mentioned above the national certificate (NCLIS) was abolished when technikons were closed (Meyer 20I0).

The fact that general library workers constitute $45.8 \%$ of employees in LIS and archival services in South Africa (Department of Arts and Culture 2010:xviii), should be reason enough for the LIS industry to be concerned about the fact that formal training of general library workers is currently receiving scant attention at institutions of higher education. Concerns, which senior library staff in their official capacity raised with LIS educators at Unisa (Van Aswegen 2006; Brown 2007; Pretorius 2007), and other concerns raised from public platforms, such as the radio talk programme: "Praat Saam" (RSG 2008), seem to point to the need for more structured training of library workers. In this way, they will be better prepared for their tasks when they are appointed.

Low qualifications of such a substantial number of library staff also have consequences for remuneration of library workers. As indicated before (Meyer 2010), municipalities or smaller local government structures are responsible for the 
appointment of staff at public and related libraries under their jurisdiction. Depending on the financial strength of local authorities there can be vast differences in remuneration offered by the market, as salaries are not necessarily standardised (Department of Arts and Culture 2010:84-85). Owing to misconceptions, it seems that posts in libraries under jurisdiction of local governments often have to compete for funding from the same budget as sport. Apparently, unqualified people are often appointed in professional positions to save money (Department of Arts and Culture 2010:95, 155).

\subsection{In-service training}

Normally tasks performed in the various sections of a library are interdependent. Some are more complex in nature, and require the application of subject-related knowledge and skills, while others are of a routine nature and need to be performed regularly in support of the successful accomplishment of an assignment. General library workers usually learn how to perform routine tasks within the context of the work situation. At the workplace, workers not only learn how to perform the activities as such, but also learn about the organisation and learn how to work together with colleagues. Workers quickly learn which role each has to play in order to ensure that productivity is achieved. Hodkinson (in Sheeres, Soloman, Boud \& Rooney 2007:15) posits that learning at work cannot be separated from everyday working practices at the workplace.

The types of tasks that general workers perform in libraries are of such a nature that these tasks can easily be learned just by watching, and staff of individual libraries could offer in-service training to suit their specific requirements. However, these arrangements have disadvantages in the sense that supervisory staff would give in-service training only when the need arose. This implies that individuals may gain piecemeal experience of the relevant procedures and practices. Lately, owing to rationalisations in LIS, supervisory staff members of many public libraries have increasingly come under pressure and they no longer have the capacity to attend to in-service training fully.

Currently, public and related libraries seem to depend on individuals in the library profession or at tertiary institutions to offer workshops from time to time to introduce or refresh their staff (including semi-professionals) to the basic principles of library-specific tasks such as cataloguing and classification, indexing, internet searching, reference work, IT instruction and collection development.

Considering that general library workers have not received prior training in library work, but perform primarily routine library tasks, it seems obvious that hands-on training is of paramount importance. However, a careful study of the job descriptions of support staff from a couple of public libraries (City of Johannesburg 2008; Ekurhuleni Metropolitan Library Services 2008; Tshwane Community Libraries 2008) showed that general library workers perform similar tasks in the respective sections of a library in general. This implies that basic tasks in libraries can ideally be offered in a workintegrated learning programme at an educational institution.

Work-integrated learning is closely linked to cooperative education where partnerships between educational institutions and business and industry are formed. However, Engelbrecht (2003:4) reports that cooperative education is still managed on an ad hoc basis in South Africa. A growing concern seems to be that partnerships between business and industry and educational institutions are not as sound as they could be (Engelbrecht 2003:9). This seems also true of the relationship between the LIS industry and library schools at educational institutions (Department of Arts and Culture 2010:160).

From the above it seems that the core problem currently experienced in terms of training of general library workers revolves around the fact that the latter have no prior knowledge of library resources, facilities, processes and procedures and yet the types of tasks they perform require them to be "work-ready".

In addition, advances in information and communication technologies (ICTs) brought more automation into libraries, and require workers not only to be library literate but also to understand how to work physically with electronic facilities and to be experienced enough to assist library users with routine operations of library resources and equipment. Savolainen (200I) identified the following criteria in order to be compliant in the current information context. Since general library workers operate within the current information context, one can assume that these criteria apply equally well to them - although to a lesser extent than to professionals:

- Awareness of networked information sources: users should know what is available in digital format and how the information is organised on the internet.

- Knowledge of the different information and communication technology tools that provide access to information such as web search engines, and an understanding of the different functions of an IT system (menu-driven instructions, command language, use of the mouse, et cetera.

- The ability to know how to search, and how to specify and refine searches by broadening or narrowing key word searches, to surf between hyperlinks and to evaluate search results. 


\subsection{Problem statement}

Considering the variety of problems identified so far, it seems that the core problem revolves around the fact that there is a void in terms of appropriate training for library workers in the LIS environment.

Owing to Unisa's involvement in curriculum development, the core question for the Department of Information Science is to determine whether the Department should develop an appropriate learning programme to prepare general workers for the job market in LIS. To do so, data have to be collected pertaining to the following sub-problems:

- Does the number of general library workers in public and related libraries justify the introduction of a vocational learning programme?

- What types of knowledge and skills should be covered in a programme relevant to the workplace?

- What types of tasks do general library workers perform in public and related libraries?

- What expertise and skills deficiencies are currently experienced in public and related libraries?

- What problems are experienced in terms of in-service training offered by supervisory staff in public and related libraries?

- What support can be offered in terms of practical training in a work-integrated learning programme?

\section{Methodology}

The survey method was used to obtain information on the viewpoints of supervisors in public and related libraries in terms of the need for training of currently employed general library workers under their supervision. The research design used in the study can be classified as a two-stage design, the first involving exploration in the form of a literature review and the second dealing with empirical research in the form of a formal descriptive study. The literature review proved to be useful to gain a better understanding of the problem of unqualified library workers, which will ultimately influence the effective rendering of public library services. Documentation in the form of job descriptions of various library services served as basis for developing the questionnaire. The job descriptions covered the types of tasks library workers perform and revealed the type of interaction with fellow staff members, contact with the user public and management, and knowledge of relevant legislation. In addition, a selection of supervisory staff of provincial and municipal libraries was interviewed to compare the responses of the interviewees to the data obtained from the questionnaire.

To speed up the process of collecting contact details, directorates of the Provincial Library Services were contacted telephonically to obtain reliable information. It was also necessary to select libraries with updated e-mail addresses and exclude libraries that did not have e-mail and internet access. This resulted in a final sample of $32 \mathrm{I}$ libraries that could be surveyed.

Judgment sampling as a type of purposive, non-probability sampling was selected from the lists received from the respective provincial library services to draw a representative sample from the sample frame. A purposive, nonprobability sample is a subjective process in which population elements do not have a random chance of being selected (Cooper \& Schindler 2003:201).

Time and budget constraints necessitated the use of a web-based survey: www.surveygizmo.com. Of the 321 e-mail addresses used for the distribution of the questionnaire, 7 I bounced back as "undeliverable", despite the fact that updated versions of the address lists were used. This resulted in a final number of 250 qualifying respondents, of whom only 60 returned their questionnaires. Ten of these returned incomplete questionnaires that could not be used. In the end, 50 correctly completed questionnaires were acquired. This is equivalent to a $20 \%$ response rate, which can be considered an exceptionally high figure in view of the generally accepted rate of approximately $10 \%$ for surveys of this kind.

\section{Findings}

For purposes of this article only, findings relating to the challenges of "work- readiness" of general workers, as public and related libraries experience it, will be discussed. Findings relating to challenges experienced by LIS educators in distance learning have been discussed in the first article (Meyer 2010). The results from the questionnaire are compared to responses obtained from the interviews with supervisory staff.

4.1 Qualifications of general library workers

From the investigation, it is evident that the majority of general library workers are not specifically trained to perform tasks in a library setting. Figure I shows that within the libraries that participated in the survey, 4I9 library workers (38\%) have a formal (SAQA-accredited) tertiary LIS qualification, $73(7 \%)$ have a tertiary qualification, but not a LIS tertiary qualification, and the remaining library workers (55\%) have no tertiary qualification whatsoever. This implies that almost two thirds of all library workers represented had no LIS tertiary qualifications. 


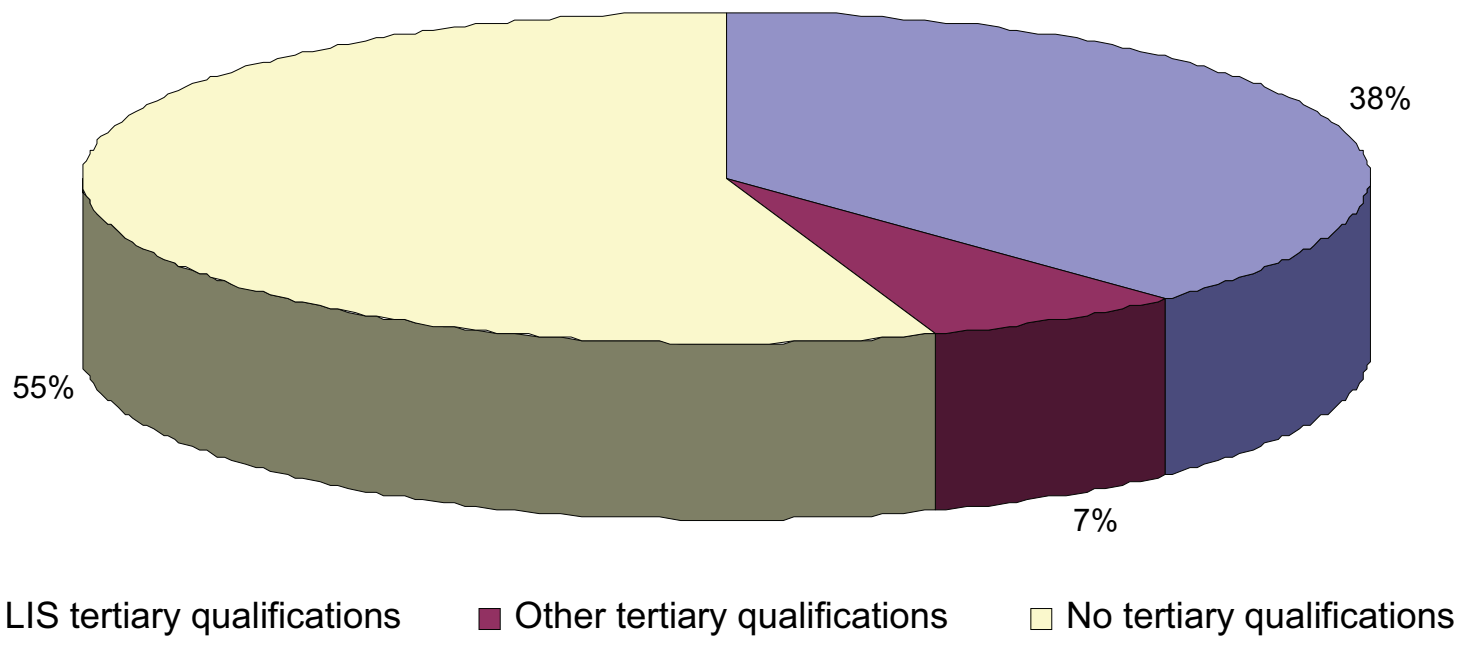

Figure 1 Qualifications of general library workers

Apart from the percentages given above, great enthusiasm was observed among interviewees for the possible introduction of an accredited qualification for library workers. Comments at open-ended questions also revealed a keen interest in such a programme. The following comments received from respondents are proof of an intense desire experienced by supervisors for the training of library workers:

- "A lot of these staff members' morale is low. They do not show dedication in library activities. All they do is complain about management and salaries. There is a need to give them advanced training about customer service."

- "Advanced training will somehow boost their [library workers'] morale and might even reduce their negative thinking."

- "Most of the library workers are exposed to many of the listed tasks in the questionnaire - however, responsibility remains with the librarian for reference work, programmes, weeding, selection, etc."

\subsection{Offering of in-service training}

With regard to in-service training, $70 \%$ of the respondents indicated that they offered in-service training to their staff. Forty per cent regularly send their workers to workshops, and $21 \%$ indicated that they could not afford to have library workers being away from their office for too long. However, almost one third $(28 \%)$ indicated that they did provide funding for formal LIS training, and $25 \%$ indicated that they provided funding for library workers attending short learning programmes (non-formal LIS training) offered at accredited educational institutions.

During the interviews some supervisors indicated that it would be far more time and cost effective if they could appoint library workers with an elementary LIS qualification that would introduce the basic requirements of library work. These supervisors also mentioned that they did not always have enough time or staff to assign to the in-service training of library workers. Much emphasis was placed on the fact that all newly appointed staff needed a work-integrated component in their training. This need is even more pronounced for library workers who have to understand why routine tasks should be performed in a structured manner, and why they should take responsibility for the respective tasks assigned to them.

\subsection{Mastering administrative tasks}

Library workers are normally assigned to routine tasks dealing with the maintenance and smooth running of library services, such as answering telephones, filing correspondence, sorting and shelving books, tracing missing periodical numbers, membership registration, issuing library material, et cetera. Results set out in figure 2 show that more than half of the general workers normally perform these tasks successfully. However, during the interviews, supervisors raised concerns about newly appointed library workers who are often incapable of performing these types of tasks efficiently. 


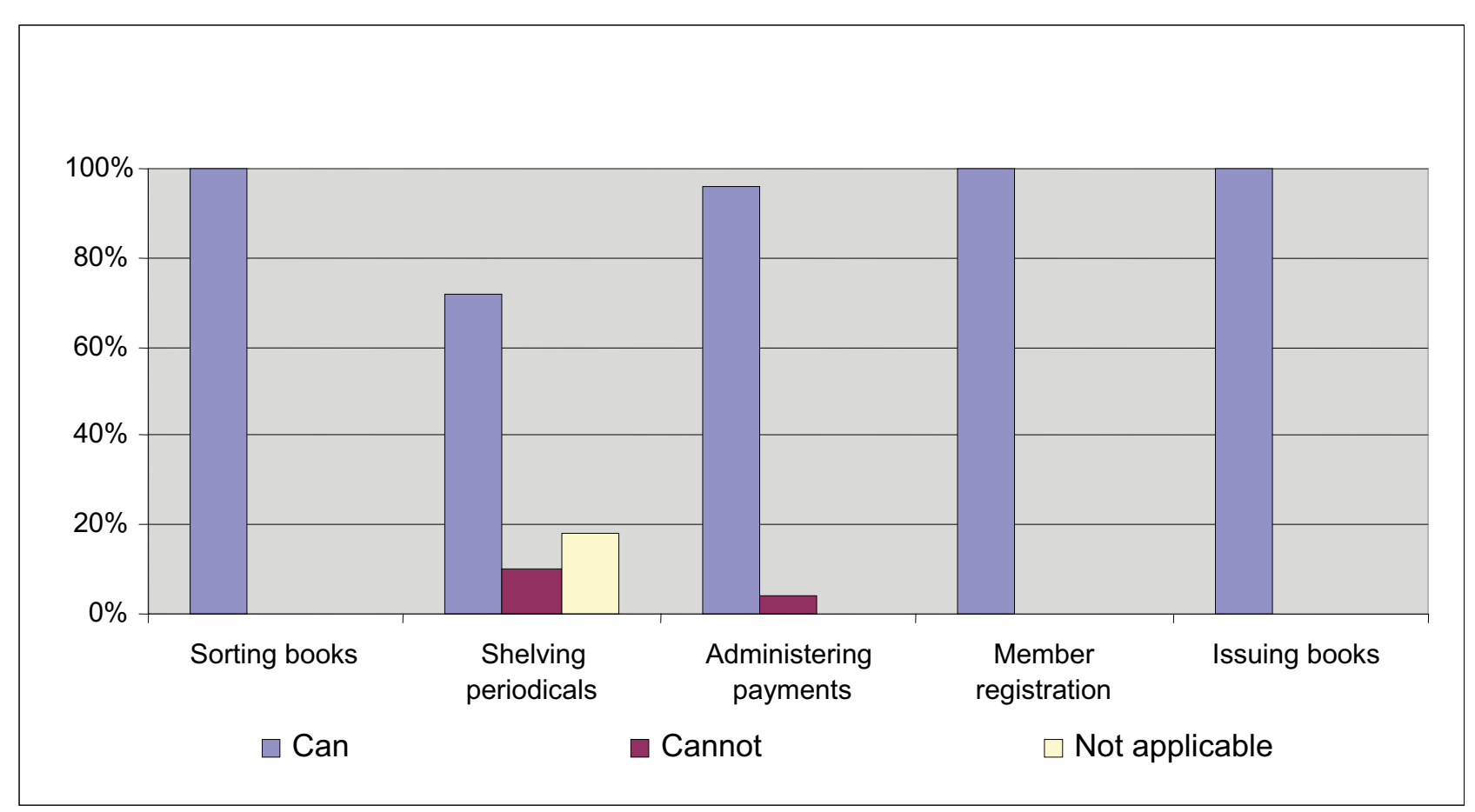

Figure 2 Mastering administrative tasks

Typically, these tasks require some basic knowledge of library stock, users and functions and a certain level of intellectual, technical and social competency. Although most of these tasks are performed in libraries, not all of them are assigned to all library workers.

\subsection{Mastering literacy and numeracy skills}

It seems that in the appointment criteria for general library workers, it is taken for granted that library workers who completed Grade 12 are literacy and numeracy skilled and have the ability to interpret instructions. However, practising librarians complained that many of their library workers fared poorly in tasks in which these competencies were required. They were of the opinion that library workers needed more task-related training in order to cope with general tasks in a library context. Results listed in Table I indicate that more than half of the supervisors prefer that a training programme for library workers should cover basic training of tasks requiring a higher literacy and numeracy competency.

Table I Training required for literacy and numeracy skills

\begin{tabular}{|c|c|c|c|}
\hline Level of practical training required & No Training & Basic Training & Advanced Training \\
\hline Responding to enquiries received from management by e-mail or letters & $28 \%$ & $68 \%$ & $4 \%$ \\
\hline Filling in forms & $32 \%$ & $62 \%$ & $6 \%$ \\
\hline Reading the instructions to remove/install cartridges for printers & $30 \%$ & $60 \%$ & $10 \%$ \\
\hline Reading and responding to circulars & $36 \%$ & $54 \%$ & $10 \%$ \\
\hline Replying to enquiries from publishers & $42 \%$ & $48 \%$ & $10 \%$ \\
\hline Checking invoices against goods received & $28 \%$ & $66 \%$ & $6 \%$ \\
\hline Cashing up & $34 \%$ & $46 \%$ & $20 \%$ \\
\hline Reconciling weekly cash income and completing documentation for treasury and the bank & $28 \%$ & $52 \%$ & $10 \%$ \\
\hline Keeping statistics (e.g. circulation, reference enquiries, membership) & $24 \%$ & $46 \%$ & $30 \%$ \\
\hline Reporting problems to supervisor or management in writing & $18 \%$ & $66 \%$ & $16 \%$ \\
\hline Enquiring about maintenance services when needed & $24 \%$ & $66 \%$ & $10 \%$ \\
\hline
\end{tabular}

\subsection{ICT and manual skills requirements}

The geographical distribution of public and related library services in South Africa can range from urban areas with a highly sophisticated ICT infrastructure to remote rural areas with a poor ICT infrastructure. This implies that in the first 
instance, library workers will need to be proficient in IT skills in order to perform their daily tasks and assist users in using available facilities and resources. Therefore, mastering ICT skills will be a prerequisite. Although manual skills (such as manual sorting and filing) will be taken for granted, they might not be in such a huge demand. However, in areas with a poor ICT infrastructure where personnel and users are dependent on printed collections and manual processes, workers will be required to perform library tasks manually. Under these circumstances, good knowledge of and skills in handling manual processes will become imperative.

It was therefore necessary to determine to what extent ICT skills training is required countrywide to perform typical tasks in public libraries, and whether ICT skills should be covered in a work-integrated training programme for library workers. Respondents had to indicate how much and what level of training their workers need in the use of ICT to perform their respective tasks satisfactorily. The results, displayed in figure 3, indicate that the majority of libraries require, to a greater or lesser extent, ICT-skilled library workers for the tasks listed in Table 2.

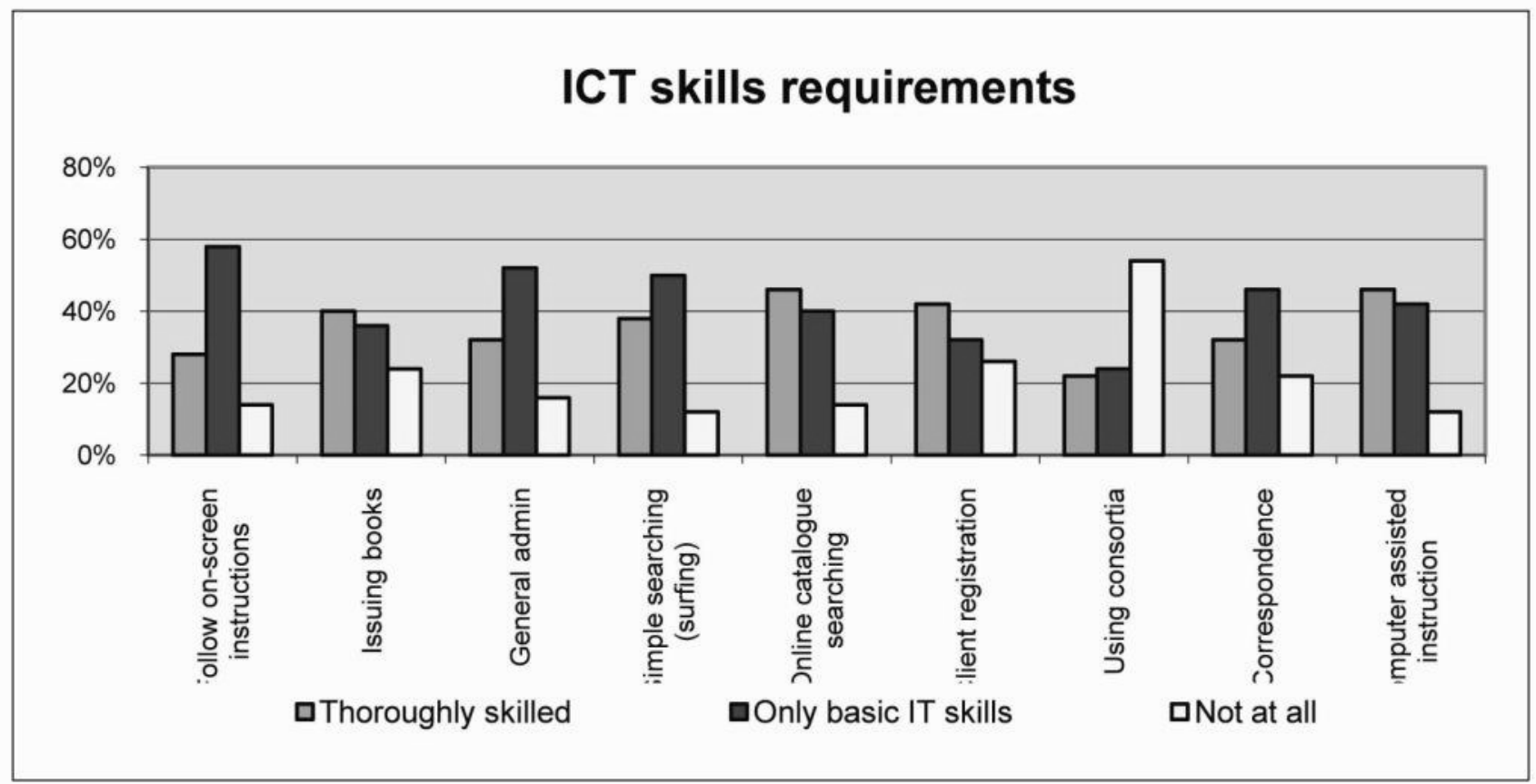

Figure 3 ICT skills requirements

From the results, it was also learned that in the sample libraries only 287 workers required training in the use of ICTs. The relatively small number of workers requiring ICT training could be ascribed to the fact that some of the employer institutions already provide basic ICT training free of charge to their employees on a standing basis. However, 287 remains a significant number for library workers who are not ICT skilled and who cannot handle computerised support facilities. Table 2 reveals the types of tasks performed by general workers, which require knowledge of ICTs and ICT skills.

Table 2 Tasks requiring ICT skills

\begin{tabular}{|c|c|c|c|}
\hline Tasks requiring ICT skills & Thoroughly skilled & Only basic IT skills & Not at all \\
\hline Following instructions on computer screen: drop-down menus, etc. & $28 \%$ & $58 \%$ & $14 \%$ \\
\hline Issuing or renewing books & $40 \%$ & $36 \%$ & $24 \%$ \\
\hline General administrative tasks & $32 \%$ & $52 \%$ & $16 \%$ \\
\hline Simple searching (surfing the internet) & $38 \%$ & $50 \%$ & $12 \%$ \\
\hline Searching information in online catalogues/databases (navigation) & $46 \%$ & $40 \%$ & $14 \%$ \\
\hline Registering clients & $42 \%$ & $32 \%$ & $26 \%$ \\
\hline Using consortia (e.g. Gaelic) & $22 \%$ & $24 \%$ & $54 \%$ \\
\hline Responding to e-mail enquiries (administrative and reference enquiries) & $32 \%$ & $46 \%$ & $22 \%$ \\
\hline Offering computer-instructed assistance to users & $46 \%$ & $42 \%$ & $12 \%$ \\
\hline
\end{tabular}




\subsection{Interpersonal relationships}

Although library workers are primarily assigned tasks in which they do not necessarily have direct contact with the user public, they often find themselves in situations where they do have to interact with the user public. Therefore, general workers also need to demonstrate socially sound interpersonal competencies. They should understand the basic operations of a library to be able to interact sociably with colleagues, management and users alike. Respondents' opinions were required to determine at what level these matters should be covered in a training programme for library workers.

The results in Figure 4 reveal that supervisors agree overwhelmingly (88\%) that library workers should be trained properly to understand how to interact with users and colleagues in face-to-face situations.

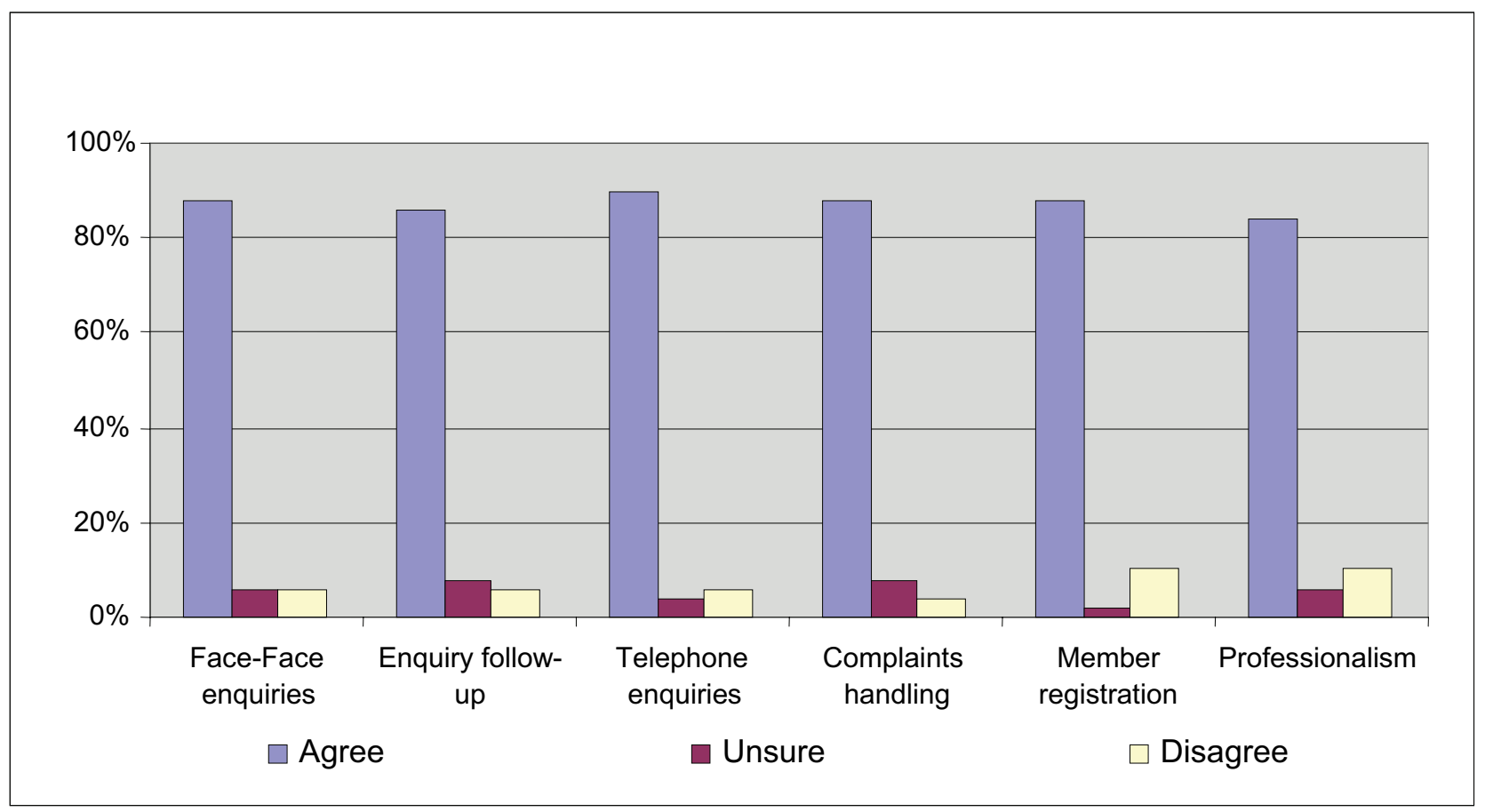

Figure 4 Training required in interpersonal relationships

From this high level of response, it can be deduced that supervisory staff are currently experiencing such poor social conduct among workers that they believe this issue should be addressed by an appropriate training programme.

4.7 Caring about the workplace and auxiliary services

Apart from supervisors raising the need for library workers to know how to perform various tasks, they were concerned about an indifference observed among library workers regarding their working environment and taking care of library facilities, and their attitude towards their work and the user public in general.

Although it is difficult to probe attitude, open-ended questions in the questionnaire allowed respondents the opportunity to air their views and to reflect on concerns or needs. The majority of supervisors (88\%) indicated a need for training in caring about the workplace to ensure a more positive attitude among library workers.

The following comment reveals something about the reason why supervisors would like caring about the workplace to be covered in a training programme for library workers:

Very few workers care about neatness and maintenance. They need to be reminded all the time. It is not easy to keep a public place (toilets, etc.) in working condition due to theft and vandalism (very high). Time management and ethics form part of our internal training.

In a question on ethics at the workplace, more than half (56\%) of the supervisors indicated a desire that workers should have a thorough knowledge of work-related ethics to contribute to the smooth running of a library service and to prevent behaviour that could compromise effective service delivery. 
Furthermore, the concern about an attitude of indifference among library workers is reflected in the following remarks by respondents, which endorsed the viewpoints of most of the supervisors interviewed:

They [recently appointed library workers] also project no interest to learn more about the contents of their libraries or e-resources - taking it for granted that the [user] public must be able to help themselves... If it were only possible to teach them the reason why they actually studied and what is expected of them, namely to serve the public in an informed and knowledgeable manner.

Often library staff under supervision of the librarian have an 'I'm not in charge' attitude, which leads to a lack of good service in the absence of the librarian. All library workers must learn that they are as much responsible for the library and library material which will result in fewer losses and less expenditure.

Apparently, this is also true of library workers involved in auxiliary tasks in a support capacity. Most public and community libraries offer auxiliary services to provide in the needs of their users, or to raise awareness about existing library material that covers topical issues that might be of interest to the public.

In responding to the question on auxiliary tasks, portrayed in figure 5, the majority (more than 60\%) of supervisors confirmed that it was extremely important that training of library workers should make the workers aware of their support role in auxiliary services. In response to the open-ended question, one supervisor suggested training in the upkeep of the pamphlet collection that children use in school tasks. These tasks include, among others, exhibitions, collections for school tasks and workshop presentations.

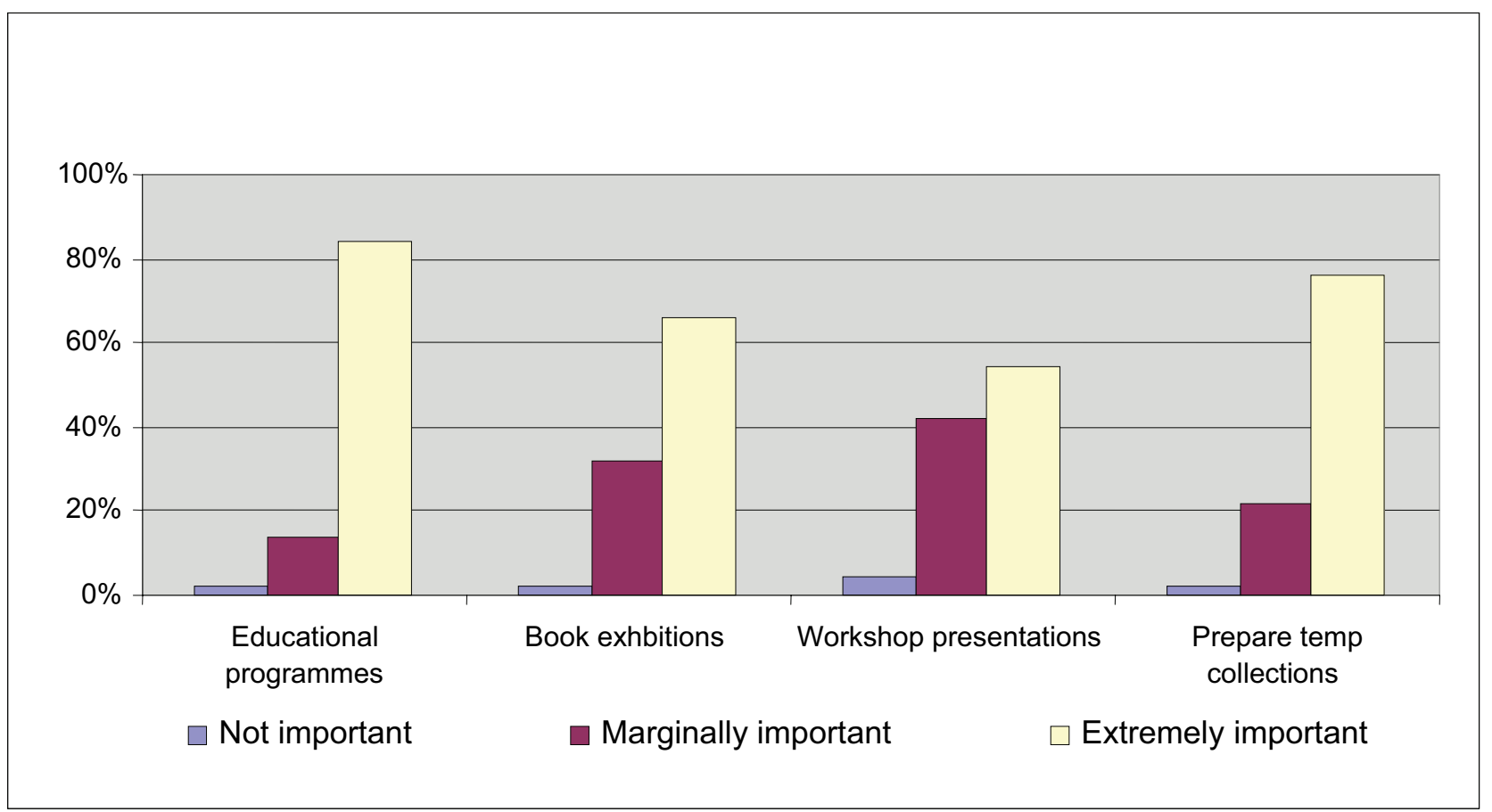

Figure 5 Training in auxiliary tasks

\subsection{Options for training}

Since learning programmes to train general library workers vary in terms of standard and duration, respondents were requested to indicate their preferences. The results reflected in Table 3 showed that Successive workshops to train basic library skills and a Certificate course with a work-related component (distance learning) received an equal rating of $61 \%$, followed by Short learning programmes (non-formal) with $53 \%$. 
Table 3 Types of work-related training (multi responses were possible)

\begin{tabular}{|l|l|}
\hline Work-related training required & $\%$ \\
\hline Successive workshops for training basic library skills & $6 \mathrm{I}$ \\
\hline Short learning programmes (non-formal) & 53 \\
\hline Certificate course with a work-related component (distance learning) & $6 \mathrm{I}$ \\
\hline Advanced certificate course with a work-related component (distance learning) & 4 \\
\hline Diploma, including practical component on organisation and retrieval (distance learning) & 4 \\
\hline
\end{tabular}

\subsection{Partnerships for practical training}

Because the nature of library workers' activities is task related, it is crucial for any training programme to include handson demonstrations and practical exercises in a real-life situation. Without the collaboration of LIS, it would be very difficult for any tertiary institution to comply with the work-integrated component of such a learning programme. Therefore, it was necessary to determine the level of collaboration that respondent libraries are prepared to offer.

From the results in figure 6 , it was evident that the majority of respondents' $(38 \%)$ are prepared to offer only limited support. They indicated that they had sufficient task variety and facilities, but limited staff. They were willing to negotiate with educational institutions about the tasks in which they could offer assistance, but they would need training guidelines. Only $4 \%$ indicated that they were well equipped to assist and had fixed schedules for work-related training, but would like to negotiate with the tertiary institution.

Considering the conditions for support from the LIS sector, it seems clear that a concerted effort will be required from educational institutions to set up working relations with libraries in order to accommodate students for practical training purposes.

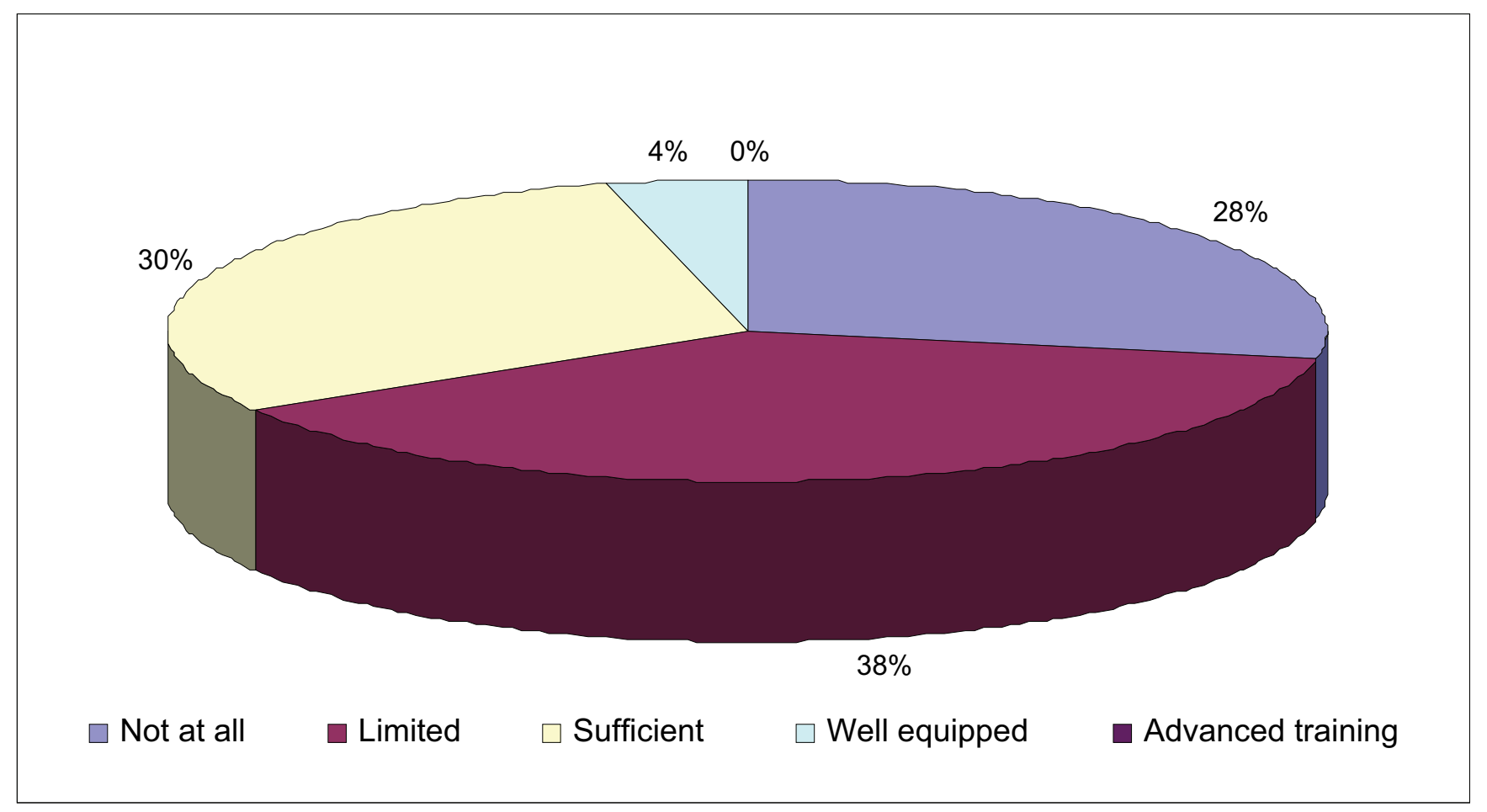

Figure 6 Infrastructure to support practical training 


\section{Discussion}

A careful study of the results of the survey, job descriptions of general library workers, and the literature study on workrelated training proved that the types of tasks that general workers perform are clearly of a routine nature. However, the culture of a library, its rules, sanction systems and expectations that should be honoured could be bewildering for a worker who only has to demonstrate generic skills at a literacy and numeracy level of Grade 12. When the nature and contents of formal tertiary learning programmes for LIS professionals are compared to the nature of the tasks performed by general library workers, it is clear that learning programmes for the latter should be approached differently. A learning programme with a much stronger vocational component, including the mastering of manual and ICT skills as applied in a library context, will be required.

In the absence of background knowledge of the LIS discipline, it seems that general library workers would benefit much more from a programme in which modules are designed around the types of tasks performed within the different sections of a library, rather than coverage of sub-sections of the discipline.

Apart from the fact that general library workers should know how to carry out procedures of routine tasks, it is evident from the results that workers should have an understanding of why they need to perform tasks according to set standards. They must also have a broader perspective of the functions of a library and of where they fit into the bigger picture, and that they do not work in isolation from the rest of the staff. In fact, they need to understand that they are in the first line of operation and that the smooth flow of tasks depends on their ability to accomplish these tasks within the set period.

Another important thing learnt from this investigation is that general library workers in the different libraries perform similar types of tasks. However, socio-economic conditions in the South African context require that general library workers be familiar with both manual and ICT skills, as the infrastructure and affordability of library services in urban and rural environments may vary substantially.

\section{Conclusion}

This presentation attempted to provide a glimpse of the experiences, needs and desires of supervisory staff in terms of inservice training of general library workers in public and related libraries in South Africa. Insights gained from the investigation give a good idea of the types of tasks assigned to general workers and the need of supervisory staff to work with "work-ready" general workers in order to alleviate their workload and to prevent unnecessary delays caused by ignorance and an attitude of indifference towards their work by some of the workers.

Considering the existing state of affairs in terms of training needs of general library workers, it is recommended that a better partnership between LIS practitioners and LIS educators be negotiated for a work-integrated component of the envisioned learning programme. Logistics to arrive at a satisfactory agreement between the LIS practice and educational institutions will have to be considered carefully.

The design and implementation of a vocational learning programme for general library workers will afford LIS educators the opportunity to demonstrate that they will honour their educational mandate.

\section{References}

Ashcroft, L. 2004. Developing competencies, critical analysis and personal transferable skills in future information professionals. Library Review, 53(2):82-88.

Bates, A, Bates, M \& Bates, L. 2007. Preparing students for the professional workplace: who has responsibility for what? AsiaPacific Journal of Cooperative Education, 8(2): |2|-129.

Biblioteekkunde 1949. 1960. In Ad Destinatum 1908-1960, redakteur CH Rautenbach. Johannesburg: Voortrekkerpers: I 26.

Biddiscombe, R. 200I. The development of information professionals' needs for internet and IT skills: experiences at the University of Birmingham. Program: Electronic Library and Information Systems, 35(2): I57-166.

Blankson-Hermans, L \& Hibberd, BJ. 2004. An assessment of LIS curricula and the field of practice in the commercial sector. New Library World, I05(I 202/I 203):269-280.

Brown, C. 2007. Request from Ekurhuleni Metropolitan Library and Information Services regarding an information training supplier (e-mail enquiry received on 9 November 2007).

City of Johannesburg. Library and Information Services. 2008. Job description form for general library workers/assistants.

Cooper, DR \& Schindler, PS. 2003. Business research methods. $8^{\text {th }}$ ed. New York: McGraw-Hill/Irwin.

Department of Arts and Culture (DAC). 2010. The demand for and supply of skills in library and information services, archival services and records management. [Online]. http://www.dac.gov.za/publications/reports/20l0/ Final\%Report\%201520March2010.pdf. (Accessed 10 August 2010).

Department of Education. 2007. The Higher Education Qualifications Framework: Higher Education Act, 1997 (Act No. I0I of 1997). Pretoria: Government Printer.

Ekurhuleni Metropolitan Library and Information Services. 2008. Job description form for benchmarked positions: Library Assistant.

Engelbrecht, LV. 2003. Best practice of cooperative education (NRF project Ref.: 15/I/5/2/000 44).

SA JnI Libs \& Info Sci 2010, 76(2) 
Fisher, B. 2004. Workforce skills development: the professional imperative for information services in the United Kingdom. Australian Library and Information Association (ALIA) Biennial Conference, 2I-24 September, Gold Coast. [Online]. http:// conference.alia.org.au/alia2004/pdfs/fisher.b.paper.pdf. (Accessed I0 August 2010).

Gerolimos, M. 2009. Skills developed through library and information science. Library Review, 58(7):527-540.

Luo, L. 2007. Chat reference competencies: identification from literature review and librarian interviews. Reference Services Review, 35(2): 195-209.

Meyer, HWJ. 2009. The introduction of a vocational training programme for library workers in public and related libraries: a feasibility study. Unisa, Department of Information Science.

Meyer, HWJ. 2010. Training needs of general library workers, Part I: Challenges facing educators in South African institutions of higher learning. South African Journal of Library and Information Science, 76(I):64-73.

Middleton, M. 2003. Skills expectations of library graduates. New Library World, I04(I I84/I I 85):42-56.

Pretorius, K. 2007. Request from South African police services to introduce general library workers to basic reference work and customer services. (E-mail dated 10 October 2006, Pretoria).

RSG. Praat Saam [radio talk programme]. 18 July 2008.

Savolainen, R. 200I. Everyday like information seeking, in Theories of information behaviour, edited by KE Fisher, S Erdelez \& EF McKechnie. Medford, NJ: Information today: I43-I48.

Sheeres, H, Soloman, N, Boud, D \& Rooney, D. 2007. When is it OK to learn at work? The learning work of organizational practices. Journal of Workplace Learning, 22(I/2): I3-26.

South African Library Association. 1962. Annual report 196I-1962. Pretoria: SALA:24-25 (Original copy in Unisa Archives).

Tshwane Community Library Services. 2008. Job description form for general library workers.

Van Aswegen, J. 2006. Request from Ekurhuleni Metropolitan Library and Information Services to introduce their general library workers to basic reference services. (E-mail and telephonic discussions, January and May 2006).

Wilson, CS, Kennan, MA, Willard, P \& Boell, SK. 20I0. Fifty years of LIS education in Australia: academization of LIS educators in higher education institutions. Library and Information Research, 32:246-257. 